\title{
O documento arquivístico digital enquanto fonte de pesquisa
}

Henrique Machado dos Santos

\begin{abstract}
Graduação em Arquivologia pela Universidade Federal de Santa Maria . Arquivista do escritório de advocacia Martini, Medeiros \& Tonetto: advogados associados e integrante dos grupos de pesquisa CNPq-UFSM: Gestão Eletrônica de Documentos Arquivísticos (GED/A) e Patrimônio Documental Arquivístico (PDA).
\end{abstract}

Daniel Flores

Doutor em Metodologías y Líneas de Investigación en Biblioteconomía y Documentación pela Universidad de Salamanca (USal). Professor Adjunto do Departamento de Documentação e do Mestrado em Patrimônio Cultural da Universidade Federal de Santa Maria (UFSM). Líder dos grupos de pesquisa CNPqUFSM: Gestão Eletrônica de Documentos Arquivísticos (GED/A) e Patrimônio Documental Arquivístico (PDA).

http://dx.doi.org/10.1590/1981-5344/2688

Este estudo realiza uma reflexão sobre as transformações do documento arquivístico, contextualizando-o como fonte de pesquisa. Discorre-se sobre questões como a evolução das tecnologias da informação, suas consequentes vulnerabilidades e a perspectiva de acessar registros fidedignos. A metodologia consiste no levantamento bibliográfico de materiais previamente publicados, contando com livros, teses, dissertações e artigos científicos. Os dados coletados são analisados de forma qualitativa, e apresentados na forma descritiva. Tais aspectos configuram este estudo como um artigo revisão com caráter assistemático. A discussão está centrada em três pontos: confiabilidade, preservação e acesso. Estes pontos são debatidos com a finalidade de preservar documentos digitais fidedignos no longo prazo garantindo - acesso e a sua correta interpretação por parte dos usuários potenciais. Por fim, este estudo contribui para a sedimentação do documento arquivístico digital como uma fonte de pesquisa, e salienta a importância de uma 
revisão constante das práticas de preservação digital até que ela atinja a mesma expertise que a preservação tradicional.

Palavras-chave: Documento arquivístico digital; Preservação digital; Confiabilidade; Fontes de pesquisa; Acesso.

\title{
The digital archival document as research source
}

\begin{abstract}
This study makes a reflection on the transformations of archival document, contextualizing it as a source of research. Are discussed issues such as the evolution of information technologies, their consequent vulnerabilities and the prospect of accessing reliable records. The methodology consists on lifting of bibliographic material previously published, with books, theses, dissertations and scientific articles. The collected data is analyzed qualitatively and presented in a descriptive way. These aspects make up this study as an article review with unsystematic. The discussion focuses on three points: reliability, preservation and access. These points are discussed in order to preserve reliable digital documents in long-term ensuring access and its correct interpretation by potential users. Finally, this study contributes to the consolidation of digital archival document as a source of research, and stresses the importance of a constant review of digital preservation practices until it reaches the same expertise that traditional preservation.
\end{abstract}

Keywords: Digital archival document; Digital preservation; Reliability; Search sources; Access.

Recebido em 19.01.2016 Aceito em 26.09.2016

\section{Introdução}

A evolução das tecnologias da informação, e a propagação de suas ferramentas, ocasionou o advento dos documentos digitais na Arquivística. Tal fato tornou necessária a criação de novas teorias, bem como a reformulação de conceitos preexistentes.

A Arquivística vem redefinindo seus traços epistemológicos e pragmáticos, e o documento arquivístico digital tem considerável 
influência sobre esta transformação. O documento mudou sua forma; o arquivo mudou seus meios de acondicionamento; o arquivista mudou suas bases teóricas e suas atividades práticas; e desta forma, a Arquivística se transforma como um todo.

Os documentos arquivísticos em meio digital possuem diversas especificidades com relação ao seu tratamento. Há notáveis mudanças quanto às atividades de criação, aquisição, classificação, avaliação, descrição, conservação e acesso. Neste sentido, surgem questões como a gestão eletrônica de documentos e a preservação digital, solidificando a necessidade de implementar sistemas informatizados nos acervos. Observa-se que um documento arquivístico poderá tramitar exclusivamente em meio digital, desde a sua produção até o acesso, tal fato conduz ao pensamento de que as mudanças na área são profundas, não só na teoria, mas também na prática.

Considerando o exposto, este estudo tem por finalidade realizar uma reflexão sobre as transformações do documento arquivístico, enfatizando o seu valor como fonte de pesquisa. Para isto são perpassadas questões como: a evolução das tecnologias da informação; as vulnerabilidades implícitas frente à preservação; e o acesso às fontes de pesquisa fidedignas.

O método utilizado é descritivo, e parte do levantamento bibliográfico de materiais previamente publicados, configurando-se como um artigo revisão de caráter assistemático. A análise dos dados coletados é realizada através do método qualitativo, contando com livros, teses, dissertações e artigos científicos indexados no Google Scholar. (GIL, 2010; LUNA, 1997; SILVA; MENEZES, 2005).

\section{Da evolução tecnológica à demanda por documentos digitais}

A adesão de documentos digitais pela sociedade pode ser analisada sobre dois aspectos, que são basicamente: a evolução das ferramentas tecnológicas; e as vantagens que os documentos digitais apresentam sobre os seus equivalentes em suportes tradicionais. Tais fatos impulsionaram o uso de ferramentas e documentos digitais nas mais diversas áreas do conhecimento, tendo impacto tanto no contexto das organizações, quanto nas atividades de pesquisa.

\subsection{O advento das tecnologias da informação}

O uso de softwares vem se expandindo para a sociedade em virtude dos avanços tecnológicos. Tal fato gera o aumento da informação registrada em meio digital, e tem impactado na maior disponibilidade e heterogeneidade destes registros (DE SORDI, 2008).

Além disto, observa-se que é neste contexto de evolução que ocorre o aumento do volume da produção de documentos arquivísticos (SOUSA, 2007; 2008). Logo, os arquivos têm que se adaptar a produção de 
documentos em suportes eletrônicos, desenvolvendo metodologias adequadas para gestão, preservação e acesso.

Os avanços das tecnologias da informação tiveram impacto direto na arquivística, observa-se que os mecanismos de registro e os meios de comunicação mudaram, assim como os arquivos (RONDINELLI, 2005). Desta forma, as ferramentas informáticas se incorporaram nos arquivos, integrando a gestão, a disseminação e a descrição de documentos digitais e tradicionais (BELLOTTO, 2006). Sendo assim, as tecnologias da informação exercem um papel intermediário na produção e na preservação das fontes de pesquisa. Logo, destaca-se que as tecnologias não se constituem em uma finalidade para a salvaguarda destes registros, e sim, em um meio para facilitar a sua gestão, preservação e acesso.

Ressalta-se que as tecnologias da informação exercem um papel renovador na contemporaneidade, e trazem a perspectiva de um futuro cada vez mais orientado ao meio digital. Neste contexto, a informação se configura como um novo potencial para o desenvolvimento econômico e social, com necessidades específicas quanto ao seu tratamento (LOPES, 2007). A informação digital trás consigo diversas vantagens, e desta forma, há um processo de transição entre o físico e o digital, porém, este processo não se trata de uma ruptura, e sim de uma readaptação para o contemporâneo. Prova disto é que a informação está sendo registra por meio de documentos eletrônicos e tradicionais, havendo o aumento da produção de ambos os registros. Há um destaque aos registros em meio digital, em virtude de seu volume, diversidade, e é claro, por se tratar de uma inovação ainda recente.

A sociedade está dependendo cada vez mais da informação gerada e registrada em computadores, o que vêm impactando, por exemplo, nas atividades de ensino e pesquisa. Desta forma, o avanço do conhecimento requer a preservação em longo prazo destes registros, sendo possível acessá-los e decodificá-los de modo que os usuários consigam interpretálos corretamente (SAYÃO, 2010).

A adesão de tecnologias da informação transformou o mundo do trabalho e da pesquisa, proporcionando novos meios de comunicação científica e organizacional. Consequentemente, a dependência estabelecida entre a sociedade e a tecnologia da informação é imensurável, pois a eficiência de diversas atividades está relacionada, direta ou indiretamente, à inovação tecnológica.

\subsection{Vantagens dos formatos digitais}

A demanda por tecnologias da informação impulsionou o uso de ferramentas digitais, o que resultou no advento do documento digital, que é a informação registrada em suportes acessíveis por meio de um equipamento computacional. Salienta-se que parte destes registros tem caráter arquivístico em virtude de sua relação orgânica, e desta forma, há uma influência tecnológica sobre as fontes de pesquisa contemporâneas. 
O meio digital proporcionou facilidades quanto ao gerenciamento de informações. Desta forma, salienta-se a redução de custos e a otimização da criação, tramitação e difusão da informação arquivística (BRASIL. Conselho Nacional de Arquivos, 2004). As fontes de pesquisa, que tradicionalmente estavam atreladas aos arquivos ganham novas perspectivas de acesso e difusão. Isto se aplica aos documentos gerados em meio digital, como também aos documentos convertidos ao meio digital, por exemplo, através de um scanner.

A difusão digital se configura como um novo caminho a ser explorado na arquivística, basta considerar o atual cenário onde a sociedade esta cada vez mais conectada à grande rede de computadores. Além disto, novas perspectivas de interação em meio digital vêm surgindo dia após dia, demonstrando que a relação entre as pessoas, e entre às instituições vem sendo cada vez mais orientada ao meio digital. Neste sentido, o uso da internet como meio de difusão corrobora para o aumento do acesso às fontes de pesquisa, gerando maior visibilidade aos repositórios institucionais e temáticos, e consequentemente, aumentando o acesso (visualização e download) aos documentos arquivísticos digitais.

Há um volume considerável de informações sendo produzido e armazenado em meio digital. Podem-se citar diversas facilidades como, por exemplo, a capacidade de produzir, editar e revisar documentos, além da possibilidade de distribuí-los mundialmente. Além disto, é possível resolver problemas de armazenamento, no que tange ao espaço físico relacionado aos grandes conjuntos de documentos arquivísticos em papel (INTERPARES 2 PROJECT, 2007b).

Observa-se que já há certo grau de familiarização dos usuários frente ao meio digital, e isto facilita a expansão do uso de formatos digitais para as mais diversas áreas do conhecimento. No entanto, ao arrolar vantagens do documento digital frente ao documento tradicional, não se propõe uma conversão dos documentos tradicionais existentes. A questão-chave é produzir novos documentos em meio digital para reduzir o espaço físico de armazenamento. Este é um ponto que vem gerando interpretações erradas tanto pelo público geral, quanto pela comunidade de pesquisa.

O documento digital não veio para substituir o documento tradicional, e sim para facilitar determinados casos onde o modelo tradicional se demostra restrito. Além disso, em meio a sua demanda não se pensou em mecanismos para garantir a sua confiabilidade, tal fato demonstra a necessidade de estudos que explorem a manutenção da integridade e da autenticidade destes registros.

\section{A confiabilidade em meio digital}

O documento arquivístico digital apresenta uma série de disparidades em relação ao documento tradicional. Observa-se que de maneira implícita às questões de gestão e preservação, existe a necessidade de comprovar a fidedignidade dos registros custodiados pelo 
acervo. Isto porque a informação registrada em meio digital é muito volátil, e está sujeita às diversas intempéries que poderão colocar em risco o acesso e a confiabilidade dos documentos arquivísticos.

O documento arquivístico digital contempla uma série de vantagens, no entanto, a ausência de procedimentos adequados de segurança e de preservação ameaça sua confiabilidade, autenticidade e acesso. E uma vez que estas propriedades são depreciadas, o documento perde o seu valor como evidência (ROCHA; SILVA, 2007). Neste sentido, observa-se que a demanda por documentos digitais vêm ameaçando a capacidade de utilizar os arquivos como fontes confiáveis. Tal fato se justifica pelas vulnerabilidades do meio digital, as quais os documentos arquivísticos estão condicionados (THOMAZ, 2005).

O documento digital possui um novo suporte, e consequentemente, características próprias quanto à produção, classificação, avaliação, descrição e presunção de autenticidade (SOUSA, 2007). E considerando que estas mudanças têm impacto direto no que tange a sua gestão, preservação e acesso, surge a necessidade de adequar os documentos digitais para o âmbito da arquivística. Para isto, criam-se teorias, e conceitos são redefinidos a fim de contemplar a realidade digital.

Documentos digitais são dotados de complexidades e especificidades derivadas exclusivamente de sua natureza. Há uma enorme facilidade para alterar e excluir estes registros, o que coloca em risco a preservação da integridade e da autenticidade destas fontes de pesquisa.

Mesmo assim, por certo tempo estimou-se que os documentos digitais estariam livres de problemas relacionados ao acondicionamento, degradação do suporte, obsolescência, falta de confiabilidade e espaço de armazenamento. Entretanto, este pensamento se mostrou equivocado, pois além da tecnologia não solucionar estes problemas, ela ainda incluiu novos problemas. E para solucionar ou mesmo minimizar estes "novos problemas" se faz necessária a interferência humana bem como a definição de políticas de preservação digital (INNARELLI, 2011).

Há uma urgência em se preservar os documentos digitais, pois as sociedades contemporâneas têm a perspectiva de que os registros produzidos estejam acessíveis no longo prazo. Desta forma, o avanço vertiginoso das tecnologias aliado a sua dependência pode levar a perdas catastróficas (MÁRDERO ARELLANO, 2008).

Neste contexto observa-se que a preservação das fontes de pesquisa requer a compreensão dos problemas oriundos da própria tecnologia e a consequente busca de soluções. O principal objetivo consiste em preservar a documentação através de um método confiável, que garanta a manutenção da integridade e da autenticidade, bem como a capacidade de interpretação dos documentos digitais por tecnologias do futuro, as quais ainda são desconhecidas. 


\section{A preservação e a pesquisa em acervos digitais}

O uso da informação registrada requer a preservação fidedigna dos documentos arquivísticos, bem como a garantia de acesso contínuo no longo prazo. Para isso, empregam-se métodos de manutenção da integridade e da autenticidade, bem como sistemas de busca informatizados que possibilitem a pesquisa documental.

\subsection{Preservação de documentos arquivísticos digitais}

A expansão das Tecnologias da Informação e Comunicação, e o consequente aumento da produção de documentos digitais, reforçam a necessidade de iniciativas de pesquisa com ênfase nas políticas de preservação digital (INNARELLI, 2007). Observa-se que estas tecnologias embora sejam recentes, já são estão presentes nos mais diversos setores da sociedade.

A evolução tecnológica pode ser considerada um caminho sem volta (INTERPARES 2 PROJECT, 2007b), pois o mundo do trabalho e da pesquisa está dependendo de ferramentas informáticas para execução de suas atividades cotidianas. Esta realidade também é expressa em considerável parte dos acervos arquivísticos, logo, não há como retroceder ao passado.

As mudanças tecnológicas impactaram sobre os documentos de forma que a preservação destes não será mais voltada para atividades de restauração, conservação e acondicionamento. Há uma ruptura na qual o principal objetivo será a migração contínua e emulação do conteúdo que define o documento digital (FONSECA, 2005). Desta forma, é preciso preservar a capacidade de representar o documento digital, de modo que sejam mantidas as suas propriedades significativas para garantir sua correta interpretação.

A popularização do acesso à internet, e o desenvolvimento de ferramentas tecnológicas para acessar a informação científica impulsionaram a expansão do campo de pesquisa para o meio digital. Desta forma, diversas soluções tecnológicas em gerenciamento e armazenamento da informação começaram a ser implementadas. Dentre as questões mais pertinentes à evolução das tecnologias, destaca-se a preservação digital em longo prazo (MÁRDERO ARELLANO, 2008). Esta prática adiciona novos desafios tanto para bibliotecas, quanto para os arquivos, que além de preservar documentos em formatos tradicionais, também deverão preservar aqueles em formato digital (HEDSTROM, 1998).

Esta mudança do paradigma da pesquisa, a qual era tradicionalmente concebida por meios impressos, representa um novo desafio para os preservadores e usuários em geral. O público pesquisador que frequenta as bibliotecas começa a acessar bibliotecas digitais e revistas científicas online; do mesmo modo, os pesquisadores dos 
arquivos estão acessando documentos digitais, sejam eles, digitalizados ou nato-digitais (born-digital).

Neste cenário de expansão e valorização dos registros digitais, torna-se fundamental assegurar o acesso em longo prazo com garantia de integridade e autenticidade. Para isto, é preciso estabelecer procedimentos estruturais e operacionais a fim de contemplar as complexidades e as especificidades dos documentos digitais.

\subsubsection{Estratégias de preservação digital}

Diversos estudos vêm discutindo a implementação de estratégias de preservação digital com ênfase nas estratégias de migração, emulação, encapsulamento, refrescamento e preservação da tecnologia. Os resultados mostram que nenhuma estratégia é capaz de solucionar todos os problemas ocasionados pela obsolescência tecnológica (BAGGIO; FLORES, 2012; CORRÊA, 2010; FERREIRA, 2006; GRÁCIO; FADEL, 2010; HEDSTROM, 2001; HEMINGER; ROBERTSON, 2000; LOPES, 2008; MÁRDERO ARELLANO, 2008; ROTHENBERG, 1999; SANTOS; FLORES, 2015a; SANTOS, 2005; SARAMAGO, 2002;THIBODEAU, 2002; THOMAZ, 2004).

No entanto, apesar da inexistência de uma solução, pode-se afirmar que a implementação de estratégias de preservação deve ser uma prioridade dos acervos digitais. Caso contrário, não existirá nenhuma garantia de integridade, autenticidade e acesso em longo prazo (MÁRDERO ARELLANO, 2008). Embora os métodos existentes não sejam suficientes para solucionar o problema da preservação, a sua implementação é essencial, pois do contrário, as fontes de pesquisa seriam negligenciadas. Como consequência, tanto os documentos quanto a sua confiabilidade seriam perdidos.

Em linhas gerais, o estudo das estratégias de preservação deve ser aprofundado a fim de obter o conhecimento necessário para a sua implementação em longo prazo. No contexto atual, pode-se dizer que a longevidade das fontes de pesquisa em meio digital está diretamente relacionada aos métodos utilizados para a preservação. Neste sentido, observa-se que além das estratégias de preservação é preciso definir uma política organizacional e implementar um repositório digital.

\subsubsection{Repositórios digitais confiáveis}

A implementação de repositórios digitais vem sendo preconizada em diversos estudos como os do Conselho Nacional de Arquivos do Brasil (2014), Fernal e Vechiato (2013), Ferreira (2006), Lopes (2008), Márdero Arellano (2008), Márdero Arellano e Leite (2009), Ramalho et al. (2007), Santos e Flores (2015c), Saramago (2004), Sayão (2010) e Thomaz (2007). Com base nesses estudos já se pode identificar um consenso com relação a necessidade de definir políticas de preservação e implementar os repositórios digitais em sua conformidade. Além disso, observa-se a necessidade de se estabelecer a conformidade dos repositórios com os 
princípios arquivísticos, e ter como finalidade, o acesso à informação científica, sociocultural ou informativa.

Observa-se que os acervos digitais possuem determinadas peculiaridades no que se refere ao seu uso. Além destas, pode-se acrescentar uma série de complexidades e especificidades com relação ao seu tratamento, logo, documentos digitais são complexos por sua natureza, dotada de fragilidades que são implícitas à sua gênese em meio digital.

Neste contexto, a implementação de repositórios digitais confiáveis torna-se fundamental para garantir o acesso fidedigno aos documentos arquivísticos no longo prazo. No entanto, observa-se que o grau de confiabilidade irá depender dos procedimentos utilizados no gerenciamento da preservação, e por esta razão, as políticas organizacionais são consideradas essenciais para nortear o plano de preservação.

\subsubsection{Políticas de preservação digital}

A implementação de estratégias de preservação, bem como de sistemas informatizados deve ser fundamentada em políticas organizacionais definidas a priori. Logo, estas políticas devem considerar a manutenção de um ambiente confiável para custódia documental.

Inicialmente as políticas de preservação digital devem apontar os requisitos arquivísticos e diplomáticos, como organicidade, unicidade, forma fixa, conteúdo estável, variabilidade limitada, entre outros. Posteriormente, definem-se os critérios para questões como: a escolha das estratégias; os formatos de arquivo para preservação; os padrões de metadados; e os softwares que serão utilizados na implementação do repositório digital. Observa-se que é essencial para os sistemas informatizados estar em conformidade com os requisitos predefinidos na política de preservação. Desta forma, cria-se um ambiente confiável capaz de garantir a fidedignidade dos documentos custodiados (SANTOS; FLORES, 2015c).

Ressalta-se a importância de se estabelecer uma relação lógica entre a definição da política e a sua implementação frente às estratégias e aos repositórios digitais. É fundamental que não haja elementos que se contradigam na definição, sendo assim, ressalta-se a necessidade das normas do acervo interoperarem, a fim de garantir a sincronia entre os procedimentos de preservação digital.

Destaca-se que a política de preservação digital deverá ser planejada de modo que haja disponibilidade de recursos na execução das atividades, dentre estes, ressaltam-se os recursos tecnológicos, profissionais especializados e recursos financeiros. Pode-se dizer que estes recursos são considerados essenciais para se elaborar um plano de preservação em longo prazo. Além disso, o fato da preservação digital ser uma atividade complexa torna necessário o desenvolvimento de uma 
equipe interdisciplinar para compartilhar conhecimentos (SCHÄFER; CONSTANTE, 2012).

Com relação aos sistemas informatizados de gestão e preservação, observa-se a necessidade destes serem interligados, de modo que se estabeleça a interoperabilidade. Assim, os documentos armazenados deverão ser capturados e classificados, para posteriormente serem avaliados de maneira segura, e descritos de modo que facilitem a recuperação da informação (CASANOVAS, 2008).

Salienta-se que a eficácia da preservação de acervos arquivísticos está diretamente relacionada ao envolvimento organizacional, e por isto as partes envolvidas no fluxo documental deverão auxiliar no processo de preservação. O primeiro passo consiste em definir questões basilares, a fim de criar uma "cultura organizacional" que insira a preservação digital no plano organizacional como um todo (SANTOS; FLORES, 2015b). Desta forma, estima-se que cada setor da organização tenha em vista a necessidade de preservar estas fontes. Para isto é preciso desenvolver um programa de conscientização do valor dos documentos digitais como fonte de pesquisa.

Em resumo, as políticas organizacionais devem considerar a preservação digital em todas as fases do ciclo documental, desta forma, o documento deve ser criado visando a preservação, e preservado visando o acesso. Logo, é preciso que haja uma sincronia entre as estratégias, os repositórios e as políticas de preservação, do contrário, a perenidade das fontes de pesquisa estará ameaçada.

\subsection{2 acesso às fontes de pesquisa}

As atividades de acesso estão diretamente relacionadas às de preservação. Logo, a preservação dos documentos arquivísticos digitais deverá considerar métodos e tecnologias que facilitem o acesso ao usuário final.

Os responsáveis pela preservação prestam serviços a usuários dos mais diversos perfis. Desta forma, pode haver variação quanto aos formatos de referência adotados e também quanto aos softwares utilizados para prover o acesso às fontes de pesquisa. Logo, poderão existir mecanismos mais simples para o público geral, como o preservador também poderá criar ferramentas para auxiliar os pesquisadores do acervo (INTERPARES 2 PROJECT, 2007a).

Observa-se que tanto bibliotecas, quanto arquivos precisam fornecer os documentos em formatos que satisfaçam as necessidades de seus usuários, do contrário não estarão cumprindo com sua missão. Paralelamente, estas instituições não são capazes de atender as necessidades de todos os seus usuários potenciais (HEDSTROM, 1998). Neste ponto, há um paradoxo, é preciso atender uma demanda que não se tem condições de atender em virtude das complexidades e especificidades que o meio digital acrescentou aos acervos. 
É fundamental garantir o acesso aos documentos arquivísticos, pois esta é a finalidade da cadeia de preservação. Ressalta-se que o acesso deverá ser gerenciado pelo preservador, com certo grau de expertise, da mesma forma que as demais atividades como recebimento, avaliação, descrição e recolhimento (INTERPARES 2 PROJECT, 2007a). O acesso às fontes de pesquisa é uma atividade tão essencial quanto às demais. Neste sentido, deverá considerar a usabilidade dos materiais digitais disponibilizados, de modo que os usuários potenciais do acervo consigam interpretar corretamente os documentos arquivísticos em meio digital.

Nesta relação indissociável entre preservação e acesso, além da interpretação correta, há outros pontos fundamentais a serem destacados como a confiabilidade dos sistemas responsáveis pela preservação dos documentos arquivísticos. Os sistemas de gestão e preservação devem realizar a manutenção da integridade e da autenticidade dos documentos custodiados a fim de fornecer registros confiáveis e fidedignos aos usuários.

Identifica-se um paradoxo nas atividades de preservação digital: estima-se garantir o acesso a documentos autênticos e inalterados, no entanto, a sua preservação requer alguma alteração (THIBODEAU, 2002). Tais empecilhos reforçam a necessidade de que os métodos de preservação digital precisam ser aperfeiçoados a fim de gerar confiabilidade aos usuários. Dente estas possibilidades, salienta-se a implementação de padrões de metadados que documentem as alterações realizadas sobre os documentos digitais. Deste modo, identificam-se as alterações realizadas de maneira autorizada ou não, sendo possível mensurar se há interferência na fidedignidade dos documentos.

Em linhas gerais, o acesso deve estar sincronizado à preservação, e esta deve realizar a manutenção da fidedignidade documental, de modo que estes registros possam servir de evidência quando consultados. A preservação enquanto etapa predecessora do acesso deve fornecer material acessível e fidedigno e para isto um sistema confiável, como por exemplo, um repositório digital, é essencial. Já nas atividades de acesso a implementação de um sistema de busca intuitivo, bem como a difusão do acervo, tornam-se primordiais. Além disto, o acervo precisa manter uma linha de diálogo com o público a fim de atender as necessidades dos mais diversos usuários, bem como cumprir sua função na sociedade.

\section{Considerações finais}

O advento das tecnologias da informação e a sua entrada no campo arquivístico acarretou a demanda por documentos digitais e desta forma, um novo patrimônio documental começou a ser constituído. Este possuir uma série de complexidades e especificidades que são oriundas de sua natureza digital.

Os documentos digitais surgem para ocupar um lugar ao lado dos documentos tradicionais, não devendo se fazer distinção quanto à prioridade de tratamento. No entanto, são necessárias abordagens que 
realcem as diferenças entre os documentos digitais e tradicionais. Desta forma, o presente estudo, observou que o tratamento das fontes de pesquisa em meio digital concentra-se em três pontos fundamentais: preservação, confiabilidade e acesso.

O primeiro aspecto, a preservação, deverá ser fundamentado em estratégias estruturais e operacionais, auxiliadas por repositórios digitais que gerenciam estas atividades. Seu objetivo consiste em manter a integridade dos documentos arquivísticos, bem como dos seus componentes digitais. Para servirem de evidência, os documentos disponibilizados para pesquisa precisam estar completos, e sem manipulações no seu conteúdo intelectual.

O segundo aspecto, a confiabilidade, tem por base a definição de políticas institucionais que estabelecem requisitos para implementar estratégias e repositórios. Desta forma, estima-se desenvolver um ambiente seguro para a preservação dos documentos, que ofereça garantia de fidedignidade aos materiais custodiados, possibilitando assim, servir como fonte de pesquisa confiável.

O terceiro aspecto, o acesso, é considerado como a finalidade de todo o esforço realizado nas atividades de preservação. Inicialmente, os documentos digitais precisam ser preservados em um ambiente seguro que adicione confiabilidade aos procedimentos do acervo. Posteriormente, é preciso garantir o acesso em longo prazo, de modo que os usuários interpretem a informação de maneira correta. Neste sentido, é fundamental que as atividades de preservação digital vislumbrem o acesso, oferecendo documentos fidedignos e condições para acessá-los.

As atividades de pesquisa requerem materiais acessíveis e de fácil interpretação, o que corrobora para aumentar o nível de qualidade da própria pesquisa. Além disto, os usuários potenciais buscam por fontes confiáveis, o que vem a reforçar a necessidade de mecanismos para verificar quaisquer alterações nos documentos. Desta forma, há uma clara sincronização entre preservação e acesso, com ênfase na confiabilidade e na acessibilidade.

Ressalta-se que o núcleo duro deste trabalho se concentra em contribuir para a sedimentação do documento arquivístico digital como uma fonte de pesquisa. Para isto, apontam-se suas complexidades e especificidade, as quais são consideradas peculiaridades do meio digital, e da mesma forma, responsáveis pela necessidade de um tratamento diferenciado, quando comparado ao documento tradicional.

Em linhas gerais, a preservação de documentos arquivísticos digitais requer o desenvolvimento de metodologias e tecnologias que considerem o seu caráter arquivístico, como, por exemplo, organicidade, unicidade, fixidez, naturalidade, autenticidade e imparcialidade. Da mesma forma, a evolução dos mecanismos de registro implica em revisar constantemente esta relação entre tecnologia da informação e princípios arquivísticos. Tal fato sentencia a arquivística a uma revisão constante de suas práticas de preservação, pelo menos até que a preservação digital atinja a mesma expertise da preservação de documentos tradicionais. 


\section{Referências}

BAGGIO, C. C.; FLORES, D. Estratégias, critérios e políticas para preservação de documentos digitais em arquivos. Ciência da Informação, Brasília, v. 41, n. 2/3, p. 58-71, mai./dez. 2012. Disponível em: $<$ http://revista.ibict.br/index.php/ciinf/article/view/2043>. Acesso em: 7 dez. 2015.

BELLOTTO, H. L. Arquivos permanentes: tratamento documental. 4. ed. Rio de Janeiro: Fundação Getúlio Vargas, 2006.

BRASIL. Conselho Nacional de Arquivos (CONARQ). Câmara Técnica de documentos eletrônicos. Carta para a preservação do patrimônio arquivístico digital. Rio de Janeiro: Arquivo Nacional, 2004. Disponível em: $<$ http://www.conarq.arquivonacional.gov.br/Media/publicacoes/cartaprese rvpatrimarqdigitalconarq2004.pdf >. Acesso em: 10 ago. 2014.

BRASIL. Conselho Nacional de Arquivos (CONARQ). Câmara Técnica de documentos eletrônicos. Diretrizes para a implementação de repositórios digitais confiáveis de documentos arquivísticos. Rio de Janeiro: Arquivo Nacional, 2014.2 Disponível em: $<$ http://www.conarq.arquivonacional.gov.br/media/publicacoes/resol con arq 39 repositorios.pdf >. Acesso em: 13 ago. 2014.

CASANOVAS, I. Gestión de documentos electrónicos. Buenos Aires: Alfagrama, 2008.

CORRÊA, A. M. G. Preservação digital: autenticidade e integridade de documentos em bibliotecas digitais de teses e dissertações. 2010. $96 \mathrm{f}$. Dissertação (Mestrado em Ciência da Informação) - Universidade de São Paulo, São Paulo, $2010 . \quad$ Disponível em: $<$ http://www.teses.usp.br/teses/disponiveis/27/27151/tde-05112010105831/pt-br.php>. Acesso em: 3 jul. 2014.

DE SORDI, J. O. Administração da informação: fundamentos e práticas para uma nova gestão do conhecimento. São Paulo: Saraiva, 2008.

FERNAL, A.; VECHIATO, F. L. Repositórios digitais como ambientes de atuação do arquivista: um estudo dos princípios arquivísticos e da preservação digital nesse contexto. Informação@Profissões, Londrina, v. 2 , n. 1 , p. 103-122, jan./jun. 2013. Disponível em: <http://www.uel.br/revistas/uel/index.php/infoprof/article/view/17272>. Acesso em: 10 jan. 2016.

FERREIRA, M. Introdução à preservação digital: conceitos, estratégias e atuais consensos. Portugal: Escola de Engenharia da Universidade do Minho, 2006. Disponível em: $<$ https://repositorium.sdum.uminho.pt/bitstream/1822/5820/1/livro.pdf $>$ . Acesso em: 2 ago. 2014.

FONSECA, M. O. K. Arquivologia e ciência da informação. Rio de Janeiro: Fundação Getúlio Vargas, 2005. 
GIL, A. C. Como elaborar projetos de pesquisa. 4. ed. São Paulo: Atlas, 2010.

GRÁCIO, J. C. A.; FADEL, B. Estratégias de preservação digital. In: VALENTIM, M. (Org.). Gestão, mediação e uso da informação. São Paulo: UNESP: Cultura Acadêmica, 2010. Disponível em: <http://livros.universia.com.br/download/Livros Academicos/Gestao med iacao e uso da informacao.pdf>. Acesso em: 1 dez. 2014.

HEDSTROM, M. Digital preservation: a time bomb for digital libraries. Computer and the humanities, Netherlands, n. 31, p. 189-202, 1998. Disponível

em: < http://deepblue.lib.umich.edu/bitstream/2027.42/42573/1/10579 2004 Article 153071.pdf>. Acesso em: 1 out. 2014.

HEDSTROM, M. Digital preservation: problems and prospects. University of Michigan, USA, 2001. Disponível em: <http://www.dl.slis.tsukuba.ac.jp/DLjournal/No 20/1-hedstrom/1hedstrom.html>. Acesso em: 10 jan. 2015.

HEMINGER, A. R.; ROBERTSON, S. B. The Digital Rosetta Stone: a model for maintaining long-term access to static digital documents. Communications of AIS, v. 3, article 2, p. 2-28, Jan. 2000. Disponível em: $<$ http://dl.acm.org/citation.cfm?id =374497\&dl=ACM\&coll=DL\&CFID =514 415141\&CFTOKEN=70364297>. Acesso em: 27 jun. 2015.

INNARELLI, H. C. Preservação digital e seus dez mandamentos. In: SANTOS, V. B. (Org.). Arquivística: temas contemporâneos, classificação, preservação digital, gestão do conhecimento. Distrito Federal: SENAC, 2007. p. 21-75.

INNARELLI, H. C. Preservação digital: a influência da gestão dos documentos digitais na preservação da informação e da cultura. Revista Digital de Biblioteconomia e Ciência da Informação, Campinas, v. 8, n. 2, p. 72-87, jan./jun. 2011. Disponível em: <http://www.sbu.unicamp.br/seer/ojs/index.php/rbci/article/view/487/33 0 >. Acesso em: 7 jul. 2014.

INTERNATIONAL RESEARCH ON PERMANENT AUTHENTIC RECORDS IN ELECTRONIC SYSTEMS (INTERPARES 2 PROJECT). Diretrizes do preservador. A preservação de documentos arquivísticos digitais: diretrizes para organizações. TEAM Brasil. Tradução: Arquivo Nacional e Câmara dos Deputados. 2002-2007a. Disponível em: <http://www.interpares.org/display file.cfm?doc=ip2 preserver guideline s booklet--portuguese.pdf >. Acesso em: 9 ago. 2014.

INTERNATIONAL RESEARCH ON PERMANENT AUTHENTIC RECORDS IN ELECTRONIC SYSTEMS (INTERPARES 2 PROJECT). Diretrizes do produtor. A elaboração e a manutenção de materiais digitais: diretrizes para indivíduos. TEAM Brasil. Tradução: Arquivo Nacional e Câmara dos Deputados. 2002-2007b. Disponível em: 
$<$ http://www.interpares.org/ip2/display file.cfm?doc=ip2 creator guideli nes booklet--portuguese.pdf >. Acesso em: 9 ago. 2014.

LOPES, L. C. A gestão da informação: as organizações, os arquivos e a informação aplicada. Rio de Janeiro: Arquivo Público do Estado do Rio de Janeiro, 1997.

LOPES, V. Preservação digital. Portugal: Universidade do Minho, Guimarães, 2008.2 Disponível em: $<$ http://www.vitorlopes.com/Trabalhos/Preservacao Digital-

Vitor Lopes.pdf>. Acesso em: 28 ago. 2012.

LUNA, S. V. de. Planejamento de pesquisa: uma introdução. São Paulo: EDUC, 1997.

MÁRDERO ARELLANO, M. Á. Critérios para a preservação digital da informação científica. 2008. 354f. Tese (Doutorado em Ciência da Informação) - Universidade Federal de Brasília, Departamento de Ciência da Informação, 2008.2 Disponível $<$ http://bdtd.bce.unb.br/tedesimplificado/tde busca/arquivo.php?codArqu ivo=4547>. Acesso em: 15 jun. 2014.

MÁRDERO ARELLANO, M. Á.; LEITE, F. C. L. Acesso aberto à informação científica e o problema da preservação digital. Biblios: Revista de Bibliotecología y Ciencias de la Información, Lima, n. 35, p. 1-10, Mar./Jun. 2009.2 Disponível em: $<$ http://repositorio.unb.br/handle/10482/4937>. Acesso em 30 out. 2015.

RAMALHO, J. C. et al. XML e preservação digital. Lisboa, 2007. Disponível em: <http://repositorium.sdum.uminho.pt/handle/1822/6224>. Acesso em: 20 ago. 2014.

ROCHA, C. L.; SILVA, M. da. Padrões para garantir a preservação e o acesso aos documentos digitais. Acervo, Rio de Janeiro, v. 20, n. 1-2, p. 113-124, jan/dez 2007. Disponível em: $<$ http://www.revistaacervo.an.gov.br/seer/index.php/info/article/view/14 2 >. Acesso em: 7 set. 2014.

RONDINELLI, R. C. Gerenciamento arquivístico de documentos eletrônicos: uma abordagem teórica da diplomática arquivística contemporânea. 4. ed. Rio de Janeiro: Fundação Getúlio Vargas, 2005.

ROTHENBERG, J. Avoiding technological quicksand: finding a viable technical foundation for digital preservation. In: COUNCIL ON LIBRARY AND INFORMATION RESOURCES. A report to the Council on Library and Information Resources. Massachusetts Ave., NW, Washington, DC, 1999. Disponível

em: $<$ http://www.clir.org/pubs/reports/rothenberg/pub77.pdf>. Acesso em: 24 set. 2014.

SANTOS, H. M. dos; FLORES, D. Estratégias de preservação digital para documentos arquivísticos: uma breve reflexão. Cadernos BAD, Lisboa, $\mathrm{n}$. 
1, p. 87-101. jan./jun. 2015a. Disponível em: <http://www.bad.pt/publicacoes/index.php/cadernos/article/view/1225>. Acesso em: 1 ago. 2015.

SANTOS, H. M. dos; FLORES, D. Políticas de preservação digital para documentos arquivísticos. Perspectivas em Ciência da Informação, Belo Horizonte, v. 20, n. 4, p. 197-217, out./dez. 2015b. Disponível em: <http://portaldeperiodicos.eci.ufmg.br/index.php/pci/article/view/2542>.

Acesso em: 21 dez. 2015.

SANTOS, H. M. dos; FLORES, D. Repositórios digitais confiáveis para documentos arquivísticos: ponderações sobre a preservação em longo prazo. Perspectivas em Ciência da Informação, Belo Horizonte, v. 20, n. 2, p. 198-218, abr./jun. 2015c. Disponível em: <http://portaldeperiodicos.eci.ufmg.br/index.php/pci/article/view/2341>. Acesso em: 3 jul. 2015.

SANTOS, V. B. dos. Gestão de documentos eletrônicos: uma visão arquivística. 2. ed. rev. aum. Brasília: ABARQ, 2005.

SARAMAGO, M. de L. Metadados para preservação digital e aplicação do modelo OAIS. In: CONGRESSO NACIONAL DE BIBLIOTECARIOS, ARQUIVISTAS E DOCUMENTALISTAS, 8., 2004. Anais eletrônicos... Estoril: [s. n.], 2004. Disponível em: <http://www.bad.pt/publicacoes/index.php/congressosbad/article/view/6 40/637>. Acesso em: 4 jul. 2014.

SARAMAGO, M. de L. Preservação digital a longo prazo: boas práticas e estratégias. Cadernos BAD, Lisboa, n. 2, p. 54-68, 2002. Disponível em: <http://www.bad.pt/publicacoes/index.php/cadernos/article/view/866>. Acesso em: 10 fev. 2015.

SAYÃO, L. F. Repositórios digitais confiáveis para a preservação de periódicos eletrônicos científicos. Ponto de Acesso, Salvador, v. 4, n. 3, p. 68-94, dez. 2010. Disponível em: <http://www.portalseer.ufba.br/index.php/revistaici/article/view/4709 $>$. Acesso em: 8 ago. 2014.

SCHÄFER, M. B.; CONSTANTE, S. E. Políticas e estratégias para a preservação da informação digital. Ponto de Acesso, Salvador, v. 6, n. 3, p. 108-140, dez. 2012. Disponível em: <http://www.portalseer.ufba.br/index.php/revistaici/article/view/6449 $>$. Acesso em: 10 out. 2015.

SILVA, E. L. da; MENEZES, E. M. Metodologia da pesquisa e elaboração de dissertação. 4. ed. rev. atual. Florianópolis: UFSC, 2005. Disponível em: $<$ https://projetos.inf.ufsc.br/arquivos/Metodologia de pesquisa e elabor acao de teses e dissertacoes 4ed.pdf>. Acesso em: 13 jun. 2014.

SOUSA, R. T. B. de. A classificação como função matricial do que-fazer arquivístico. In: SANTOS, V. B. (Org.). Arquivística: temas contemporâneos, classificação, preservação digital, gestão do conhecimento. Brasília: SENAC, 2007. p. 79-172. 
SOUSA, R. T. B. de. Em busca de um instrumental teórico-metodológico para a construção de instrumentos de classificação de documentos de arquivo. In: BARTALO, L.; MORENO, N. A. (Orgs.). Gestão em arquivologia: abordagens múltiplas. Londrina: EDUEL, 2008, p. 11-52.

THIBODEAU, K. Overview of technological approaches to digital preservation and challenges in coming years. In: THE STATE of digital preservation: an international perspective. Washington: CLIR and Library of Congress, 2002. p. 4-31. Disponível em: <https://www.clir.org/pubs/reports/pub107/pub107.pdf\#page=10>. Acesso em: 19 ago. 2014.

THOMAZ, K. de P. A preservação de documentos eletrônicos de caráter arquivístico: novos desafios, velhos problemas. 2004. 389f. Tese (Doutorado em Ciência da Informação) - Escola de Ciência da Informação. Universidade Federal de Minas Gerais, 2004. Disponível em: <http://www.bibliotecadigital.ufmg.br/dspace/bitstream/handle/1843/VAL A-68ZRKF/doutorado katia de padua thomaz.pdf>. Acesso em: 28 jul. 2014.

THOMAZ, K. de P. Documentos eletrônicos de caráter arquivístico: fatores condicionantes da preservação. Perspectivas em Ciência da Informação, Belo Horizonte, v. 10, n. 1, p. 34-53, jan./jun. 2005. Disponível em: <http://portaldeperiodicos.eci.ufmg.br/index.php/pci/article/view/301>. Acesso em: 7 set. 2014.

THOMAZ, K. de P. Repositórios digitais confiáveis e certificação. Arquivística.net, Rio de janeiro, v. 3, n. 1, p. 80-89, jan./jun. 2007. Disponível em: $<$ http://www.brapci.inf.br/ repositorio/2010/05/pdf fed0720dbb 001072 6.pdf>. Acesso em: 7 set. 2014. 